\title{
A Study on Design Preference for the Sales Spaces of Duty-Free Shops by the Examination of Image Evaluation - Cases of Duty-Free Shops in Jeju Special Self-governing Province -
}

\author{
Jung-Eun Moon and Bong-Ae Kim \\ Ph.D. candidate, Department of Home Management, Graduate school of Jeju National University, Jeju Special Self- Governing Province, Jeju, Korea \\ Prof., Faculty of Human Ecology \& Welfare, Jeju National University, Jeju Special Self- Governing Province, Jeju, Korea
}

\begin{abstract}
The purpose of this study is to examine design preferences for the sales spaces of duty-free shops (DFSs) by conducting image evaluations. The results will help improve quality by influencing designs for the construction, extension or remodeling of these shops. An image measurement method, the semantic differential method, was used to measure cognitive structure using photos of shops. Photos were collected of the DFS at Jeju Island, as well as photos of brand stores designed by architects. Two sets of 16 photos (32 different photos in all) were selected according to photo classification standards and design concepts, both decided by reviewing previous studies and related materials. The evaluation and survey were done by two sets of subjects: sales employees, who have experience and special knowledge of the evaluation of sales space; and students majoring in architecture. To strengthen the evaluation results, I conducted a preliminary survey and a main survey, verifying and complementing findings. 116 surveys were conducted, of which 14 were of poor quality and rejected, leaving and 102 to be analyzed. The collected surveys were statistically analyzed, using SPSS 12.0 for Windows. Reliability, image profile, factor and multi-dimensional scaling analyses were conducted. As a result, image evaluation structure and characteristics were obtained for sales spaces of DFSs, confirming the difference between them and other spaces.
\end{abstract}

Keywords : Duty-free Shops in Jeju, Sales Space, Image Evaluation, Profile Analysis, Factor Analysis

\section{INTRODUCTION}

The duty-free product market trend in Korea shows that the number of duty-free shops (collectively called "DFSs" here after) has grown from the first DFS, Donghwa, established in 1973, to 20 shops in 2000 and 29 by 2009. In addition, the market size has grown from one billion dollars in 2000 to 2.5 billion dollars in 2009-an annual growth rate of $13 \%$, much greater than the $8 \%$ of the world brandname product market; Korea is ranked eighth in duty-free product market size ${ }^{1}$, with most income coming from foreign tourists and business people visiting the country. Thus, for national economic growth through the tourism industry, focusing on variable costs such as shopping expenditure is a lot more efficient than focusing on fixed costs such as accommodation, food and transportation expenditure ${ }^{2}$. From this perspective, effective operation of DFSs will become increasingly important, creating higher tourist spending and thus promoting greater national economic growth.

Meanwhile, the recent design trend for commercial spaces lays emphasis on the purchasing process itself, and new design concepts are being created, with varied shapes and types meeting customers' needs for quality services. Since the 1990s, retail shops have seen a new era of competition, forming mega-size fashion flagship stores (Kang, 2006) and making efforts to develop their own unique brands. Good examples of this trend are Prada Epicenters and Louis Vuitton stores; they use the store itself as a means to express their products. Thus, given that DFSs sells various high-end products as well and given the change in distribution environments, it is necessary to provide a new sales space (Moon \& Kim, 2009) design for DFSs. However, DFSs have unique characteristics, in that purchase and access are limited and customer needs have to be satisfied within the constraints of time and place. In other words, even if they are classified as a commercial space, they are quite different from other stores such as shopping centers or department stores. Thus, design guidelines on efficient and effective space layout and design must be established, just for DFSs. However, despite the uniqueness of DFSs and their effect on the economy, their design depends on commercial building manuals - there are no specific design guidelines. Therefore, studies on DFS sales spaces must be done from a new perspective before measures can be taken to improve them.

The aim of this study, therefore, is to quantitatively measure the design image ${ }^{3}$ of sales spaces, which have effect on preference; this is to be achieved by evaluation experiments applying the semantic differential method to DFSs in Jeju special self-governing province. In addition, differences in the design trends of DFSs and architects' brand shops are to be obtained by comparison and analysis of evaluation results of photos of the two types of shop. The ultimate purposes of this study are to provide design materials for qualitatively improving the design of DFS sales space, positively impress customers by improving

\footnotetext{
${ }^{1}$ Data Source: the Korea Chamber of Commerce \& Industry, GS1 Korea/2008 Annual Report for Tourism Trend, the Ministry of Culture, Sports and Tourism

${ }^{2}$ Data Source: 2008 Current state of expenses by Individual foreign travelers, the Korea Tourism Organization

3 "Image" is used in its wider sense, including abstract memory of structured past experience and association as well as a concrete figure as a result of perception. Although an individual image is very personal, communication reveals similar image patterns in groups of people. In other words, a common image exists and this trend transforms into a common style for an era.
} 
design of the sales space, and contribute to the revitalization of tourist shopping.

\section{METHODOLOGIES}

A spatial image is the sum of a number of factors, including the detailed elements comprising the space and the relationships between them. The way in which such elements are formed determines a concrete substance and image is an important factor in design. However, image is a mental phenomenon, being interpreted from the perspective of a person's mental status and disposition. Thus, methods to measure the implications of image for scientific and objective communication have been studied, and scaling methods, especially Osgood's semantic differential method (Osgood et al., 1957), have been used as an effective means for defining spatial correlations suggesting standards for technology and performance. Meanwhile, researches by Hattori Mineki et al. (1991), Choi et al. (1998), Lee \& Lim (2008) and Jung (1999) showed that photos may be used for the evaluation of a specific space. This study conducted an image evaluation experiment for an empirical analysis on design preference in a DFS's sales space using photos of sales space in order to provide subjects with a consistent evaluation source, irrespective of

Table 1. Image terms used for evaluation

\begin{tabular}{|c|c|c|c|c|}
\hline & Items & Evaluation term & Items & Evaluation term \\
\hline \multirow{4}{*}{ 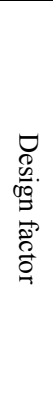 } & Space & $\begin{array}{l}\text { closed-open } \\
\text { complicated- } \\
\text { simple }\end{array}$ & \multirow{4}{*}{ 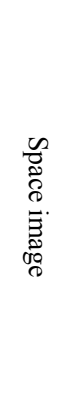 } & \multirow{4}{*}{$\begin{array}{l}\text { traditional-modern, } \\
\text { monotonous-varied, } \\
\text { natural-artificial, } \\
\text { general-unique, } \\
\text { clichéd-original, } \\
\text { not friendly-friendly, } \\
\text { lowbrow-highbrow, } \\
\text { countrified-stylish, }\end{array}$} \\
\hline & $\begin{array}{l}\text { Color } \\
\text { Light }\end{array}$ & $\begin{array}{l}\text { dark-bright } \\
\text { cold-warm }\end{array}$ & & \\
\hline & Shape & straight-curved & & \\
\hline & Texture & $\begin{array}{l}\text { hard-soft } \\
\text { rough- smooth }\end{array}$ & & \\
\hline
\end{tabular}

Table 2. Overview of duty-free shops for this study

\begin{tabular}{|c|c|c|c|c|c|c|}
\hline \multirow[b]{2}{*}{ Operator } & \multirow{2}{*}{$\begin{array}{l}\text { Opening } \\
\text { date }\end{array}$} & \multirow{2}{*}{ Location } & \multicolumn{2}{|c|}{ Area $\left(\mathrm{m}^{2}\right)$} & \multirow{2}{*}{$\begin{array}{l}\text { Ratio of shop } \\
\text { area to total } \\
\text { area }(\%)\end{array}$} & \multirow{2}{*}{$\begin{array}{l}\text { Number of } \\
\text { employees }\end{array}$} \\
\hline & & & $\begin{array}{l}\text { Total } \\
\text { area }\end{array}$ & $\begin{array}{l}\text { Shop } \\
\text { area }\end{array}$ & & \\
\hline Hotel Lotte Jeju & '00.03.25 & $\begin{array}{l}\text { Saekdal-dong, } \\
\text { Seoguipo-si }\end{array}$ & 86,401 & 2,390 & 2.77 & 101 \\
\hline Hotel Shilla Jeju & $\begin{array}{c}\text { '89.08 } \\
\text { (Inside } \\
\text { the hotel) }\end{array}$ & $\begin{array}{l}\text { Yeon-dong, } \\
\text { Jeju-si }\end{array}$ & 10,446 & 3,284 & 60.16 & 155 \\
\hline $\begin{array}{c}\text { Jeju Tourism Organi- } \\
\text { zation }\end{array}$ & '09.03.30 & $\begin{array}{l}\text { Jung-mun, } \\
\text { Seoguipo-si }\end{array}$ & 61,107 & 2,059 & 3.37 & 119 \\
\hline $\begin{array}{c}\text { Jeju Free International } \\
\text { City Development } \\
\text { Center (JDC) }\end{array}$ & '02.12.24 & $\begin{array}{c}\text { Gonghang 2ro, } \\
\text { Jeju-si }\end{array}$ & 63,300 & 1,617 & 1.30 & \\
\hline $\begin{array}{c}\text { Jeju Free International } \\
\text { City Development } \\
\text { Center (JDC) }\end{array}$ & '02.12.24 & $\begin{array}{l}\text { Gunip-dong } \\
\text { Pier 2, Jeju-si }\end{array}$ & 13,908 & 224 & 2.90 & 562 \\
\hline $\begin{array}{c}\text { Jeju Free International } \\
\text { City Development } \\
\text { Center (JDC) }\end{array}$ & '02.12.24 & $\begin{array}{l}\text { Gunip-dong } \\
\text { Pier 7, Jeju-si }\end{array}$ & 2,660 & 81.7 & 3.07 & \\
\hline
\end{tabular}

the difference in the passage of time, level of illumination and the area of eye field.

(1) Design evaluation and evaluation term selection methods

An image evaluation test measures a person's perceptive structure and uses a 7-scale semantic differential (Toyohiko, 1983). A total of 144 pairs of evaluation terminologies were gathered by reviewing previous studies (Kasmer, 1970; Lee, 1984; and Yu, 2008), and based on the results of those studies, were grouped into the two categories of design factor and space image. Design factor includes the sub-categories of space, color/light, shape, and texture, excluding terms which were relatively less frequently chosen, duplicative, or inappropriate for this study. The selected terminologies were preliminarily reviewed for their suitability and, finally, reduced to 15 adjective pairs and 1 preference question, as in Table 1 . These pairs include closed-open, complicated-simple, dark-bright, cold-warm, straight-curved, hard-soft, rough- smooth, traditional-modern, monotonous-varied, natural-artificial, general-unique, clichéd-original, not friendly-friendly, lowbrow-highbrow, countrified-stylish, and bad-good.

\section{(2) Photo selection method}

Six duty free shops in Jeju special self-governing province were chosen, excluding Lotte duty free shop at the international airport where access was denied for security reasons, for the selection of photos for evaluation (Table 2). A total of 141 photos were gathered from direct photography and homepages for the shops. Photos were taken mainly at the intersection of aisles or at main entrances where the large, open spaces of the duty free shops allowed the capture of photos of comprehensive and varied design elements without focusing only on a specific factor, such as light or color (Figure 1). The photos taken were reviewed, and photos that were too spatially restricted, too, similar, or ineffective at showing a spatial image were excluded.

Based on the literature, pictures were screened according to form of lines shape in pictures (straight, curved, 
Table 3. List of photos selected for the experiment

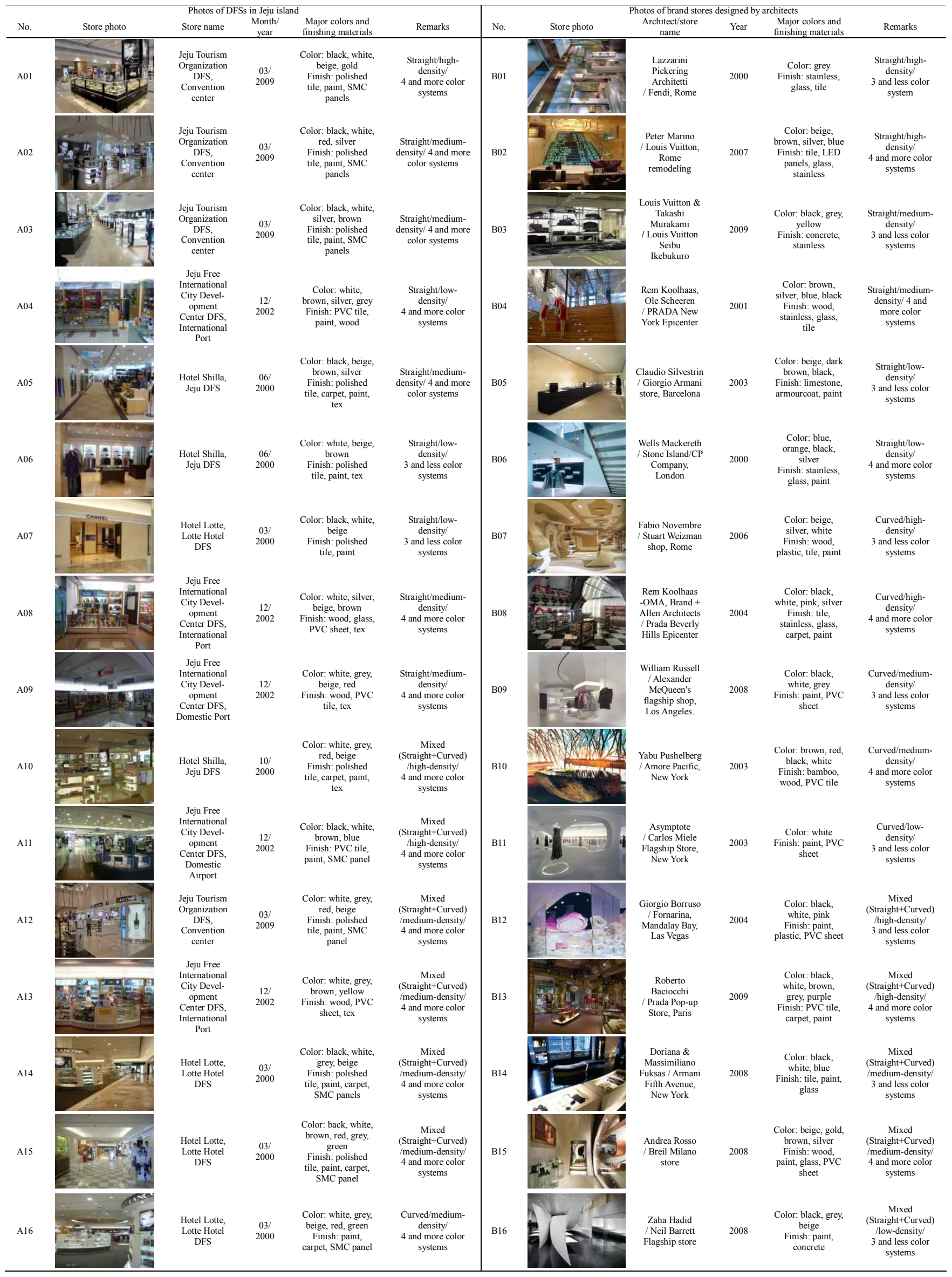


mixed $^{4}$ ), space density (high, medium, low) and number of color systems ( 3 and less, 4 and more). Finally, 16 pictures were selected that did not overlap in terms of shop atmosphere and characteristics (Table 3).

Considering that most merchandise at DFS is in the high-price range, luxury brand shops designed by architects for image comparison were examined. A total of 67 pictures from 64 brand stores were collected through architects' websites or printed materials; flagship stores of renowned brands and boutique shops were chosen that either featured in architecture literature or won architecture awards. These pictures were again screened for the final 16 cuts, centering on the architect's design concepts; all stores were built after 2000 .

The selected 32 pictures were developed on glossy printing paper $(17.1 \mathrm{~cm} \mathrm{X} 12.7 \mathrm{~cm})$ and attached to hardboard $(20 \mathrm{~cm} \mathrm{X} 15 \mathrm{~cm})$ to be presented to test participants.

\section{(3) Overview of the empirical experiment}

Students majoring in architecture major and specialist employees of DFSs were chosen because the empirical analysis requires high assessment quality. To inspect and supplement effectiveness of the analysis tool, the survey was divided into a preliminary survey (conducted on August 18 through 22, 2009) and a main survey. The preliminary study was conducted on sixteen students majoring in architecture, testing the reliability and feasibility of the experiment, image evaluation terms and selected photos. The regular study was conducted from August 28 to September 8, 2009, on 91 sales employees and 25 students of architecture. General characteristics of the subjects were surveyed first, and then the experiments were conducted by showing all 32 photos to the subjects, first photos of DFSs and then those of brand shops. Store names were not disclosed and subjects were requested to complete an image evaluation table with 16 questions for each photo. The experiment was conducted at DFSs, the subject's residence, or school classroom during the day because of the difficulty of assembling people at a designated place. 116 surveys and questionnaires were gathered and 102 chosen for analysis, excluding responses of poor quality. The materials were statistically analyzed by using SPSS 12.0 for Windows, and reliability, image profile ${ }^{5}$, factor and multi-dimensional scaling analyses were conducted. The reliability of the experiment was measured as .887 of Cronbach's $\alpha$ coefficient, showing high reliability.

\section{PREVIOUS STUDIES ON IMAGE EVALUATION AND SALES SPACE PREFERENCE}

\footnotetext{
${ }^{4}$ A review of previous studies indicated that line-drawings excluding everything except spatial outlines (Fig. 2) were used to evaluate spatial elements of a specific space for spatial image. By evaluating the linedrawings of photos, a space is categorized as a straight line type if straight lines are dominant, a curved line type if curved lines are dominant, or a hybrid type if neither is dominant. This study used these three categories.

${ }^{5}$ A profile is obtained by vertically placing all evaluation factors, marking each factor's average on the graph, and connecting the marks. It is useful in comparing and analyzing averages and is especially widely used as part of studies using Semantic Differential (SD).
}

The process of human "evaluation" of the environment has been studied in conjunction with process of perception and cognition. U. Neisser (1978), in his book $\ulcorner$ Cognition and Reality $\lrcorner$, demonstrated that "schemata" is the most significant cognitive structure in visual perception, which indicates a stand-by state that selectively filters information and controls visual activities. He advocated concept of perceptive cycle whereby one explores and extracts information on ambient vision using schemata and keeps modifying it. Applying this concept to environmental evaluation, Shimizu (1997) verified impact of physical elements on emotional response of individuals, focusing on picture images of house interior space. The result showed that spatial function and color are the most influential factors on spatial evaluation, but evaluation is a comprehensive process that is founded on more than one factor. Similarly, Moon et al. (2007) examined a schematic system that classified functional elements and sensible elements for their influence on spatial evaluation. The research concluded that individual differences and functional elements played a crucial role in spatial evaluation. These studies suggest that evaluation of a particular space is done on a subconscious level and is a comprehensive process, without being limited to a particular factor. Even though individual differences affect spatial evaluation, it is necessary to identify general factors to reflect a mass public's average preference for the design of public spaces. However, previous studies are mostly focused on residential space and have limited applicability in commercial architecture, such as DFS.

Previous studies focused on finding the degree of the effect of a specific factor on space evaluation. They tried to analyze a space by dissecting it into individual factors such as color, texture, brightness, shape, and use, and for this purpose, three types of photos were selectively used, as in Figure 2. However, this method failed to give shape to each individual factor influencing space evaluation, concluding that space evaluation is complex and comprehensive. In addition, evaluation was conducted by asking subjects to place photos on a 7-point scale, followed by interviewing them as to their reasoning. This method has limitations in producing systematic evaluation results. Therefore, to complement previous studies, the Semantic Differential (SD) method was used in this study to obtain more objective and quantitative results in data extraction and analysis.

Meanwhile, studies on design preference for sales space have focused on department stores, discount stores and marts; there has been no study for DFSs. Furthermore,

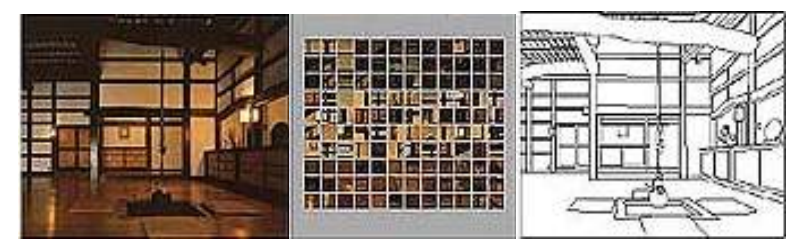

Figure 2. Photos of previous studies (original photo, image palette, and line-drawings from left) 
these studies involved a hierarchy of factors with an effect on evaluation, such as display, walking path, ornament and color 'Seo \& Choi, 1996; Choi \& Jung, 2002; Lee, 2002', and their analysis was conducted for each indoor element such as floor, wall and ceiling (Lee et al., 2007). This approach differs from the concept of this study: that overall space image determines the evaluation, rather than a specific factor. Therefore, for DFSs, this study is to analyze space from the perspective of totality in forming the image rather than focusing on a specific factor, and to explain the structure of image evaluation in evaluation terms.

\section{ANALYSIS RESULTS AND IMPLICATIONS}

\section{(1) Characteristics of subjects}

People in their 30s made up the highest percentage of participants $(64.7 \%)$, followed by $20 \mathrm{~s}(23.5 \%)$ and $40 \mathrm{~s}$ (11.8\%). The ratio of female participants $(71.6 \%)$ far exceeded that of male participants $(28.4 \%)$. This is attributed to the fact that the survey was conducted for DFS staff and architecture majors for professional evaluation. Forty-nine percent of participants had been employed for 4 years or more, followed by 3 4 years $(20.6 \%), 2 \sim 3$ years $(9.8 \%)$, $1 \sim 2$ years $(4.9 \%)$ and less than a year $(2.9 \%)$. Regarding educational background, $70.6 \%$ had a college diploma, $15.7 \%$ were attending college or graduate school, $3.9 \%$ had higher education than college diploma and 9.8\% had a high school education. For monthly income, 30.4\% earned between KRW 2 3 million, followed by KRW 1 2 million (23.5\%), KRW 3 4 million (21.6\%), over KRW 4 million

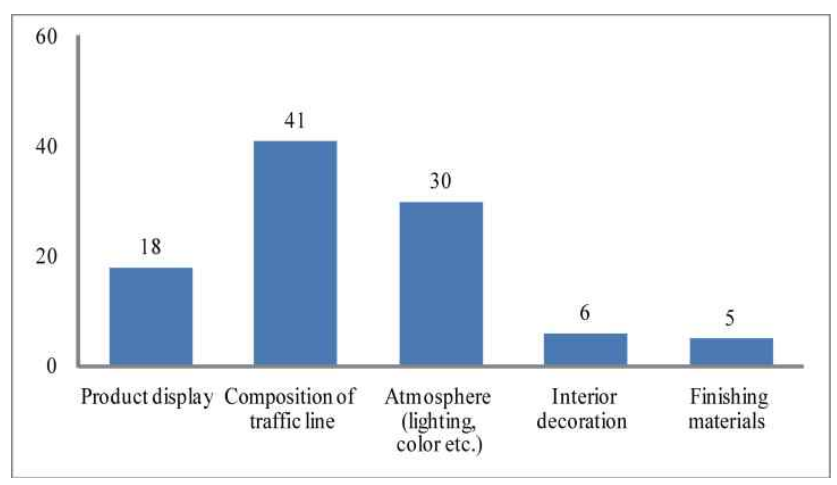

Figure 3. Evaluation basis for the shop you have been to (unit: \%)

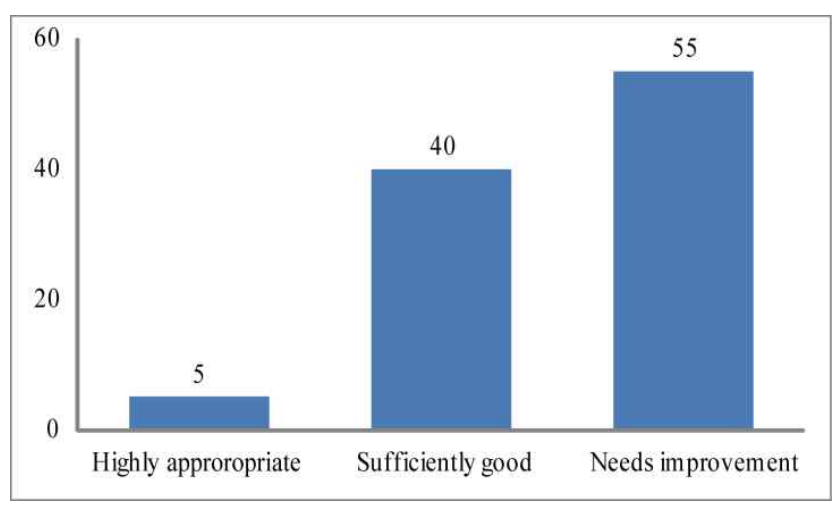

Figure 4. whether design of sales space needs to be improved (unit: \%)
(10.8\%) and less than KRW 1 million (13.7\%). Architecture majors were not asked to fill out length of employment or monthly income questions.

To a question whether a participant had visited DFS in Jeju province, $93 \%$ of the respondents gave a positive answer. Jeju airport DFS for domestic travelers showed the highest percentage of visitation (36\%), followed by the Shilla DFS (25\%) and Hotel Lotte Jeju international airport DFS (14\%). Nine percent of the respondents said they had visited the Hotel Lotte DFS and convention center DFS operated by Jeju Tourism Organization (JTO); 4\% had visited Jeju domestic port DFS, and 3\% had visited the international port DFS. Concerning the degree of satisfaction with DFS sales space, 19\% responded "excellent," $59 \%$ said "moderately satisfied," and 22\% replied "not satisfied." More than half of the respondents said that they were only moderately satisfied with DFS sales space. As for the question on evaluation criteria, $41 \%$ composition of traffic line, followed by atmosphere of lighting and color scheme $(30 \%)$, product display $(18 \%)$, interior decoration $(6 \%)$ and finishing materials $(5 \%)$; these results showed that the survey participants put more emphasis on the store's composition of traffic line and ambience in evaluating DFS sales space (Figure 3). As to whether duty free shops in Jeju province needed a better design, 55\% replied that "the design needs to be improved as it was highly different from expectation"; $40 \%$ of the respondents replied that "even though the design was different from expectation, it is good enough"; $5 \%$ remarked that "the shops have excellent design, fully meeting one's expectation" (Figure 4). This suggests that Jeju DFS sales space needs an upgraded design that considers composition of traffic line and store atmosphere.

(2) Profile analysis for the image evaluation of DFS sales space

1) Profile of DFS sales space and brand shop sales space designed by an architect

To analyze images of DFSs sales spaces, profiles of Jeju DFSs and architects' brand stores were drawn (Figure 5, 6). Based on the average value, survey participants perceived Jeju DFSs sales spaces as slightly complex, straight-lined, hard, monotonous and artificial. They thought the shops to be common, old-fashioned but mildly friendly. In comparison, participants perceived architects' brand stores as slightly complex but modern and various, with an artificial, uncommon and new-fashioned flavor. Also, even though the architects' brand stores felt a little unfriendly, they had superior and polished images.

To obtain concrete differences between the two groups, the averages of highly-preferred brand shops by architects and the average of DFSs in Jeju were compared and analyzed (Table 4). The findings show that subjects prefer sales spaces in brand shops by architects (4.77) to those in DFSs in Jeju (3.98). Items with an average difference of 1 or more were "traditional-modern" (1.03), "monotonousvaried" (1.29), "general-unique" (1.80), "clichéd-original" (1.60), and "countrified-stylish" (1.03). This implies that these are important factors for the differences between the 
two groups. Meanwhile, for "not friendly-friendly", the average difference was -0.17 , meaning higher friendliness of DFSs in Jeju and showing that friendliness does not necessarily have a positive effect on preference for sales space. This result contrasts to Moon et al. (2007)'s study that for the evaluation of residential buildings, past space experience of friendliness has a positive effect on preference. In other words, this implies that important factors for a private space evaluation of a residential building and a sales space evaluation of DFSs are somewhat different.

Table 4. Average evaluation value by items

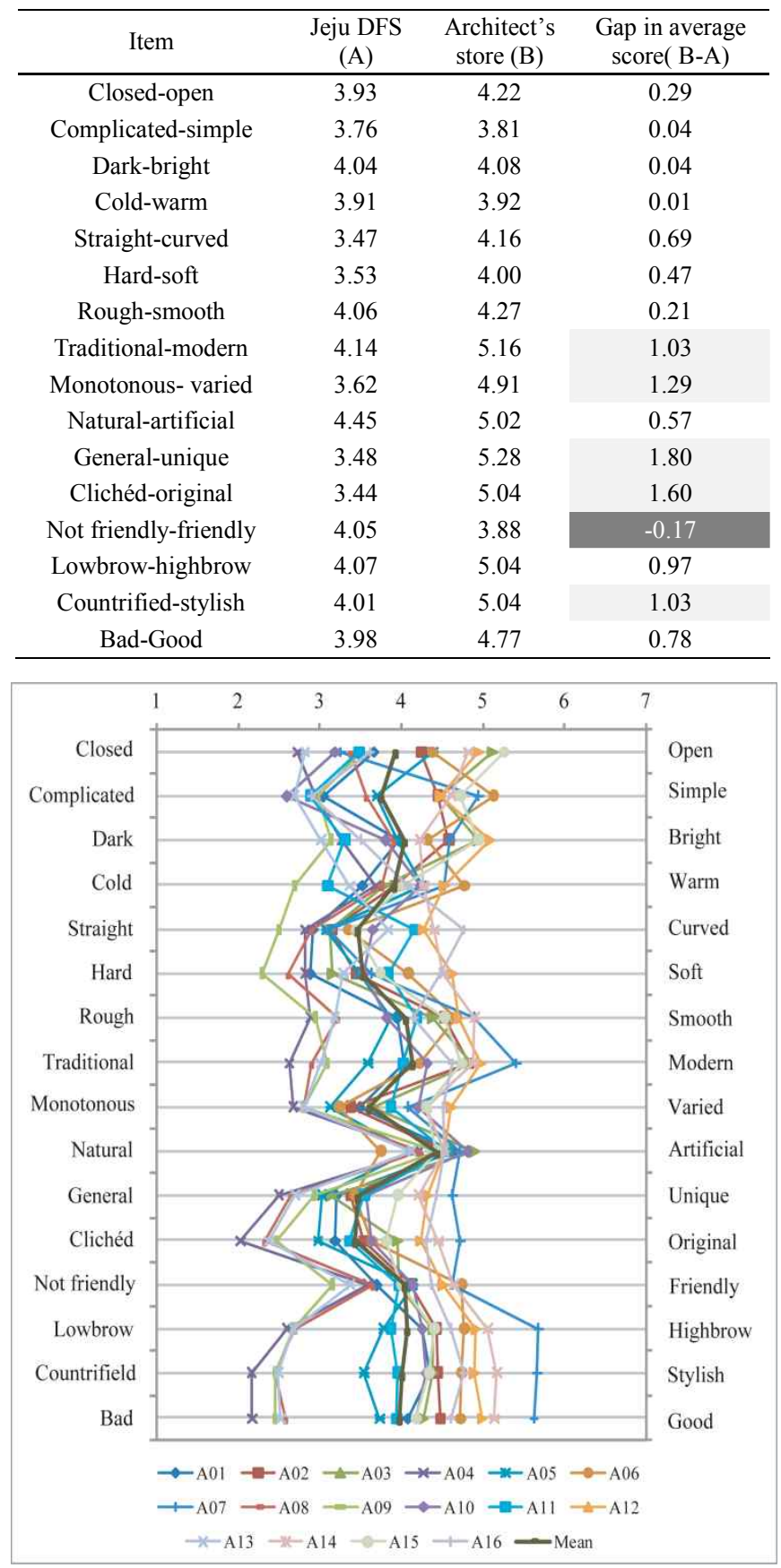

Figure 5. Image evaluation profile for the sales spaces of DFSs in Jeju
2) Profile analysis on sales space evaluation according to preference

To verify design preference through image evaluation, all photos of DFSs and brand shops were laid out in order of preference points (Table 5). As a result, eight high ranking photos with an average of 5 or more and seven low ranking photos with an average of 4 or less were identified. High ranking photos include three DFSs: A07 (5.64), A14 (5.14) and A12 (5.00); and five brand shops: B15 (5.59), B13 (5.38), B05 (5.16), B02 (5.06) and B16 (5.05). Low ranking photos include six DFSs: A11 (3.94), A05 (3.74),

Table 5. Preference ranking chart of the photos

\begin{tabular}{cccccc}
\hline Ranking & $\begin{array}{c}\text { Picture } \\
\text { no. }\end{array}$ & $\begin{array}{c}\text { Average } \\
\text { score }\end{array}$ & Ranking & $\begin{array}{c}\text { Picture } \\
\text { no. }\end{array}$ & $\begin{array}{c}\text { Average } \\
\text { score }\end{array}$ \\
\hline 01 & A07 & 5.64 & 17 & A02 & 4.49 \\
02 & B15 & 5.59 & 18 & B06 & 4.43 \\
03 & B13 & 5.38 & 19 & B12 & 4.35 \\
04 & B05 & 5.16 & 20 & A03 & 4.28 \\
05 & A14 & 5.14 & 21 & B08 & 4.28 \\
06 & B02 & 5.06 & 22 & A10 & 4.19 \\
07 & B16 & 5.05 & 23 & A15 & 4.18 \\
08 & A12 & 5.00 & 24 & B01 & 4.13 \\
09 & B04 & 4.98 & 25 & A01 & 4.09 \\
10 & B10 & 4.95 & 26 & A11 & 3.94 \\
11 & B11 & 4.81 & 27 & B14 & 3.84 \\
12 & B07 & 4.77 & 28 & A05 & 3.74 \\
13 & B09 & 4.76 & 29 & A08 & 2.58 \\
14 & A06 & 4.73 & 30 & A13 & 2.52 \\
15 & B03 & 4.72 & 31 & A09 & 2.46 \\
16 & A16 & 4.62 & 32 & A04 & 2.17 \\
\hline & & & & &
\end{tabular}

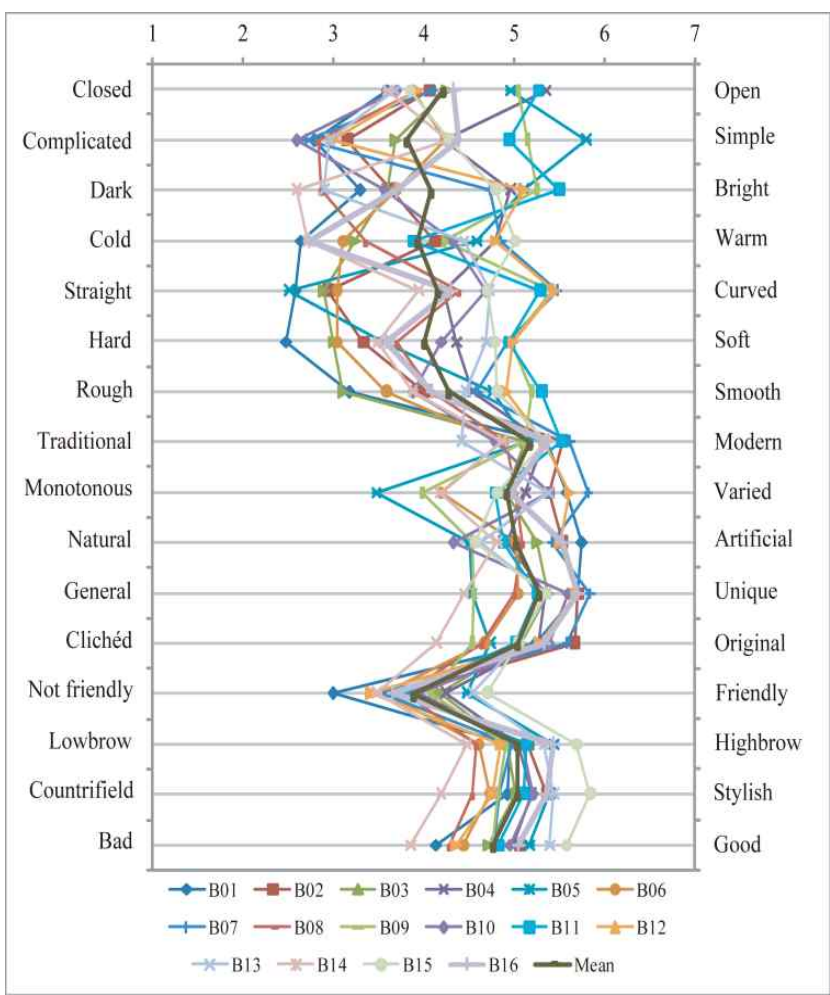

Figure 6. Image evaluation profile for the sales spaces of brand shops by architects 
A08 (2.58), A13 (2.52), A09 (2.46) and A04 (2.17); and one brand shop: B14 (3.84). The average difference between the two groups is relatively high, at 2.21 (Table 6).

Profiles were made for the selected photos of high and low rankings and analyzed (Figure 7 and 8). As a result, the items "clichéd-original" (2.09), "lowbrow-highbrow" (2.08) and "countrified-stylish" (2.35) showed a high average difference of 2 or more and are therefore important factors defining the difference between the two groups (Table 5). They were followed by "rough-smooth" (1.12),

Table 6. Average difference

between the high and low ranking groups

\begin{tabular}{cccr}
\hline Item & $\begin{array}{c}\text { Upper } \\
\text { group (A) }\end{array}$ & $\begin{array}{c}\text { Lower } \\
\text { group (B) }\end{array}$ & $\begin{array}{c}\text { Gap in average } \\
\text { score( A-B) }\end{array}$ \\
\hline Closed-open & 4.23 & 3.42 & 0.82 \\
Complicated-simple & 4.32 & 3.30 & 1.03 \\
Dark-bright & 4.26 & 3.31 & 0.94 \\
Cold-warm & 4.28 & 3.37 & 0.91 \\
Straight-curved & 3.87 & 3.32 & 0.55 \\
Hard-soft & 4.09 & 3.12 & 0.97 \\
Rough-smooth & 4.58 & 3.46 & 1.12 \\
Traditional-modern & 5.14 & 3.45 & 1.69 \\
Monotonous-varied & 4.63 & 3.19 & 1.44 \\
Natural-artificial & 4.82 & 4.36 & 0.45 \\
General-unique & 4.98 & 3.12 & 1.86 \\
Clichéd-original & 4.90 & 2.82 & 2.09 \\
Not friendly-friendly & 4.37 & 3.63 & 0.74 \\
Lowbrow-highbrow & 5.34 & 3.26 & 2.08 \\
Countrified-stylish & 5.39 & 3.04 & 2.35 \\
Bad-Good & 5.25 & 3.04 & 2.22 \\
\hline
\end{tabular}

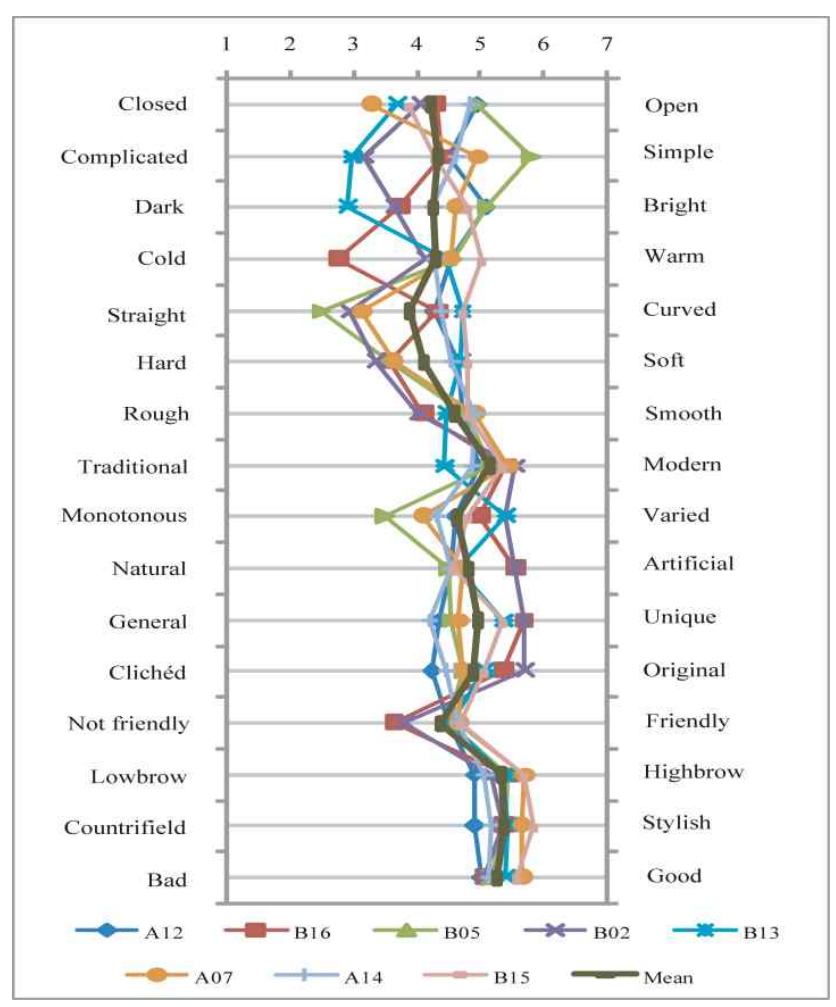

Figure 7. Profile analysis on photos of overall preference averaging 4.00 or less "traditional-modern" (1.69), "monotonous-varied" (1.44), and "general-unique" (1.86), with an average difference of 1.00 or more. The items "closed-open" $(0.83)$, "darkbright" (0.91), "straight-curved" (0.55), "hard-soft" (0.97), and "not friendly-friendly" showed an average difference of 0.5 or more while "natural-artificial" $(0.45)$ showed that of 0.5 or less.

(3) Types of image evaluation structure for the sales spaces of duty-free shops

To verify the subjects' evaluation structure for the sales spaces of DFSs, two analyses were performed on the averages of each evaluation item: principal component analysis and factor analysis by Varimax method. Table 7 demonstrates that three factors showed an eigenvalue of 1 or more, confirming the feasibility of the concept of this study. These three factors explain $65.93 \%$ of the total variables. Meanwhile, "not friendly-friendly", "lowbrowhighbrow" and "countrified-stylish" were excluded from the analysis because factor analysis showed that they are cumulative.

The first factors include five items: "general-unique", "monotonous-varied", "clichéd-original", "traditionalmodern" and "natural-artificial". Given that these words emphasize emotional evaluations of space, they are collectively termed sensibility factors.

The second factors include four items: "hard-soft", "straight-curved", "cold-warm", and "rough-smooth". As these factors determine the design elements of a space, they are termed design factors.

The third factors include three items: "complicated-

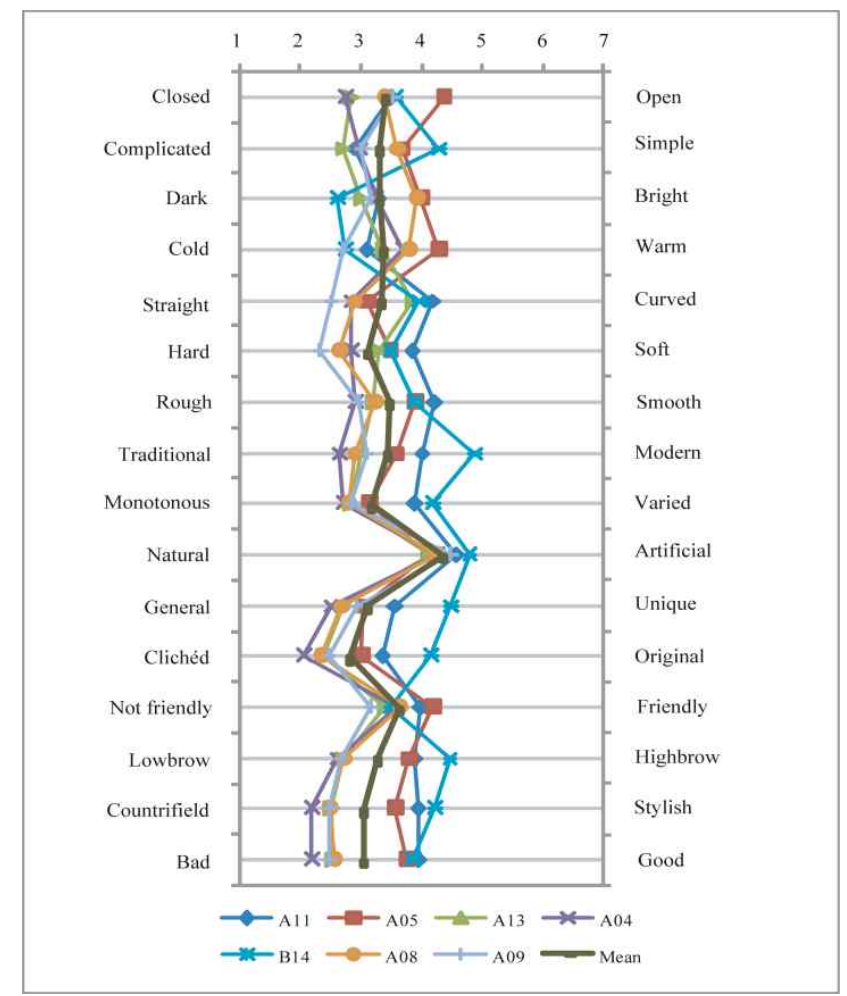

Figure 8. Profile analysis on photos of overall preference averaging over 5.00 
simple", "closed-open", and "dark-bright". They relate to space senses and are termed space factors.

The first, second, and third factors respectively show $25.48 \%, 22.49 \%$, and $17.97 \%$ of the amount of explanation. In order words, factors for duty free shops having the greatest positive effect on subjects are sensibility factors. The "general-unique" factor (.850), especially, has the greatest effect, followed by "hard-soft" (.857), and "complicated-simple" (.848). Thus, these factors must be considered for expansion of duty free shops.

The disparity difference for each photo was calculated based on the evaluation of 16 items. Multidimensional scaling analysis was conducted based on factor scores to verify the differences. As a result, photos B15 and A09 are the most distant, at 10.569 in the spatial proximity matrix and B12 and B07 are the closest, at 1.100. Figure 9 shows the scatter plot of the result. High-preference photos were indicated on a floating table as circles, low-rank as squares

The graph shows that highly preferred photos are located lower on the graph, less preferred ones higher. Differences in distance on the scatter plot can be obtained by analyzing and comparing the characteristics of photos to each item's point. Higher-ranked photos tend to be strongly original, highbrow, and stylish, rather modern but simple, smooth, and unique. In contrast, less-preferred photos tend to be strongly clichéd, lowbrow, and countrified, rather complicated, rough, traditional, simple and general.

These results, just like the factor analysis results, showed that sensibility factors are the most important, followed by design factors, then space factors. This result is rather different from Lee \& Lim (2008)'s image evaluation result for art galleries in the order of display method, space factor, and ambience. Furthermore, Jung (1999)'s research result for department interiors obtained, as major factors for the evaluation, open, simple, and straight, followed by smooth, highbrow, stylish, and bright. These can also be interpreted as design and space factors, which are more important than sensibility, and therefore different from this study's result.

This implies that evaluation criteria of DFS sales space may be different from art galleries or even department stores despite the same commercial nature.

\section{CONCLUSIONS AND DISCUSSIONS}

These are the conclusions for the image evaluation of 32 photos for seven DFSs and other brand shops designed by architects, with the object of verifying design preferences for sales spaces of DFSs in Jeju special self-governing province.

First, subjects think design improvement is urgently necessary for DFSs in Jeju; of all factors considered, they place priority on walking path and ambience (such as light and color) over product display. This implies that design needs to concentrate on the sales space itself, following the design trend for recent brand shops, and that future DFSs sales spaces must be designed to take into account customers' tendency to prefer a unique and varied sales space.

Second, to verify the image evaluation tendency for
DFS sales spaces, profiles for sales space photos of DFSs in Jeju and brand shops by architects were made and analyzed. The result showed that, for DFS sales spaces,

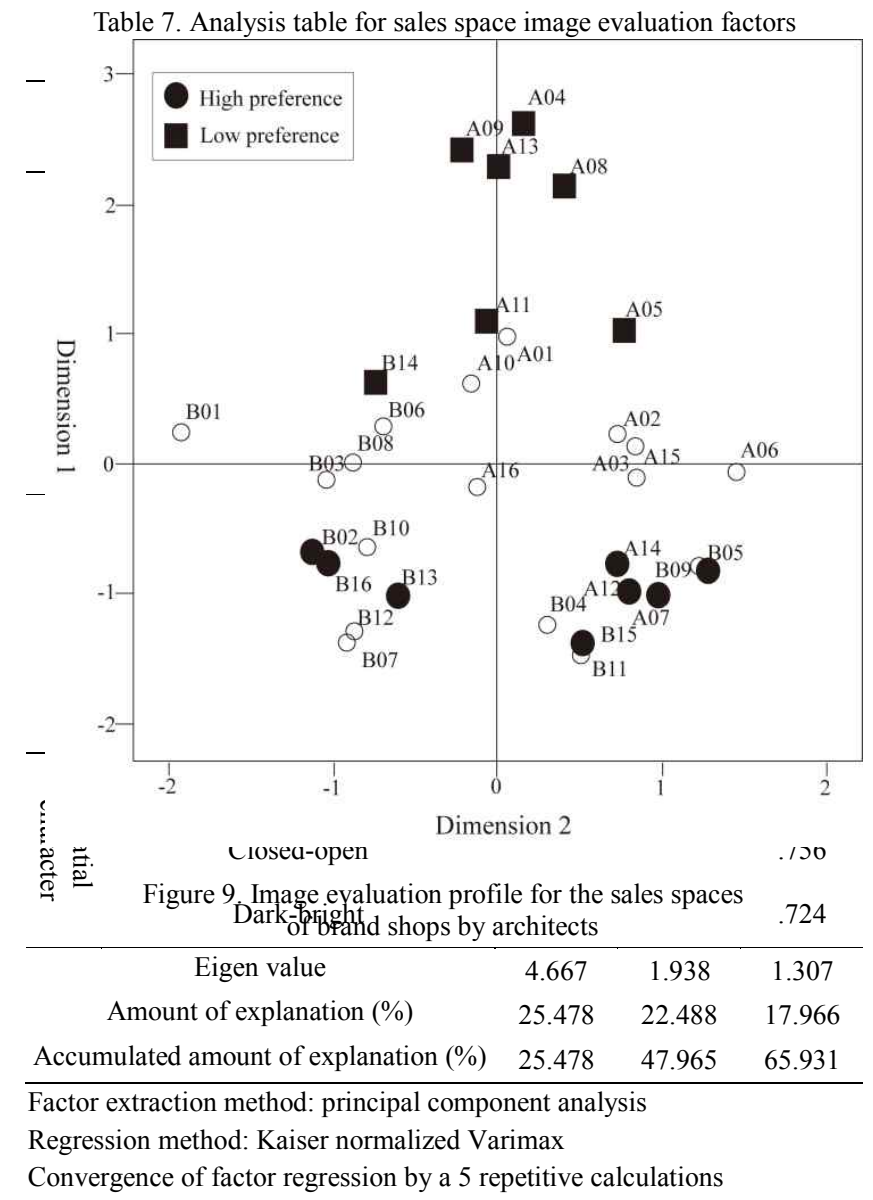


evaluation is not determined by any one factor, but by a complex combination of a number of factors with a hierarchy among them. This may seem similar to previous study results, but DFSs are different from other types of buildings (such as residential buildings) in that friendliness does not necessarily have a positive effect on preference. In addition, in the comparison between DFS sales spaces in Jeju and brand shops, "modern, varied, unique, original, and stylish" turned out to have a positive influence on preference. In profile comparison between high and low ranking groups based on overall photo preference, "clichéd-original", "lowbrow-highbrow", and "countrifiedstylish" turned out to be major factors in preference difference. This result will contribute to the guidelines to set design objectives, reflecting the effect of the factors, in designing DFS sales spaces.

Finally, a factor analysis verified the subjects' evaluation structure for DFS sales spaces. The result classified factors into sensibility, design, and space factors. Multidimensional analysis was conducted to deduce concrete preference differences among photos, and the result shows that sensibility factors are the most important influence on preference, followed by design factors and then by space factors. Meanwhile, comparison with previous studies shows that this result is different from those for art galleries and commercial spaces like department stores. In other words, sales space user preference cannot be explained by previous evaluation structures for other spaces, but requires an independent evaluation structure for DFSs alone.

Based on these results, the following design guidelines for duty free shops are suggested. To design a highly preferred space, it is desirable to focus on efficient customer movement and store ambience more than any other factors. Using the terms from this study, ideal store ambience can be described as unique, highbrow, stylish, modern, varied, and of original design. More specifically, spaces were similar to terms chosen by subjects in the order of photo numbers A07, B15, B13, B05, A14, B02, B16, and A12. These spaces have the ability to stimulate subjects' senses. These research results need to be actively applied as a design concept.

This study was made to verify the design preference for DFSs sales spaces in Jeju special self-governing province and to provide a design guideline. Future studies need to be done on detailed items such as traffic line distribution methods, and they will contribute to quality design for DFSs sales spaces by defining the interface between the space and its users.

\section{REFERENCES}

Kang, So Yeon (2006) A Study on the Characteristics of Brand Image and Design Expression Trend of Flagship Store. Doctoral thesis, Major in Interior Architecture, Department of Architectural Engineering, Graduated School of Hong Ik University: 3-4.

Moon, Jung-Eun and Kim, Bong-Ae (2009) "A Study on the Selling Space Composition Types of the Installation floor of Duty-Free Shops in Korea." Journal of Asian Regional Association for Home Economics, Vol. 16: 47-
62. (In this study, "sales space" is understood as essential space in terms of architectural planning, spatial organization and business management; it includes spaces for product sales, consumer path, convenience services, cultural spaces and others that pursue to attract visitors and accommodate acts that affect product sales.)

Osgood, C.E., Suci, G. J., Tannenbaum, P. H. (1957) The Measurement of Meaning, Urbana, Ill.: University of Illinois Press.

Hattori Mineki, Nagai Masatake, Umehara Kanae, Aksaki Kakuya (1991) "Study on evaluation system of interior space: Part-1 3." Summaries of technical papers of Annual Meeting Architectural Institute of Japan, Architectural planning and design rural planning: 65-70.

Choi, Sang Hun and Lee, Hyun Ju (1998) "An Analytical Study on the Types of Interior Design Image and Consisting Elements in the Hotel Lobby Space." Journal of the Architectural Institute of Korea, Planning \& Design, 14 (3), Architectural Institute of Korea: 3-10.

Lee, Kyoo Hwang and Lim, Che Zinn (2008) "A Study on the Extraction Structures of Gallery Environment Affecting Viewing Behavior in Art Museums - Focusing on Phychological Experiments Applied to the Repertory Grid Development Method." Journal of the Architectural Institute of Korea, Planning \& Design, 24 (9), Architectural Institute of Korea: 113-121.

Jung, Soo Hyeon (1999) A study on the Type of Interior Design Image and Consisting Elements in the Department Store - Focused on the First Floor of Department Store. Master Thesis, Graduated School of Construction Engineering, Chung an University, Republic of Korea: 54-109.

Toyohiko, Iwashita (1983) SD image measurement method - Its understanding and implementation guidance. Kawashima Bookstore: 106-130.

Joyce Vielhauer Kasmar (1970) "The Development of a Usable Lexicon of Environmental Descriptors.” Journal of Environmental and Behavior, 2 (2): 153-169.

Lee, Yeon-sook (1984) "Examination of Factor Structure of Environmental Terms that Assesses Pleasantness of Residential Environment." Journal of Korean Home Economics Association, Vol. 58('84.09), Korean Home Economics Association: 99-109.

Yu, Eun Mi (2008) "A Study on the Image Words Evaluation of Space Design." Journal of the Architectural Institute of Korea, Planning \& Design, 24 (12), Architectural Institute of Korea: 123-130.

U. Neisser (1978) co-translated by Takashi Kozaki·Akira Murase (1997) Cognition and Reality. Science Co. Ltd.: 20-21.

Shimizu Takayuki (1997) The Concept of Schemata and an Analysis of General Tendency of Evaluation: The relation between schemata and evaluation of restfulness of Interior Space. Master Thesis, Department of Built Environment, Tokyo Institute of Technology: 16-43.

Moon, Jung Eun, Kawano Eriko and Ohno Ryuzo (2007) "The Relationship between Schemata and Evaluation Residential Interior space 1-2." Summaries of technical 
papers of Annual meeting Architectural Institute of Japan 2007, Architectural Institute of Japan: 983-986.

Seo, Jong Ho and Choi Sang Hun (1996) "A Study on the Preference for the Components of the Department Store Interior Design Image - Focusing on Women Customers Resident in Seoul." Journal of the Korean Institute of Interior Design 9, Korean Institute of Interior Design: 39.

Choi, Sang Hun and Jung, Young Ho (2002) "A Study on the Characteristics of Interior Design Image Types and Space Components of Women's Wear Part in the Department Store - Focusing on the City Department Stores in Seoul Area." Journal of the Korean Institute of Interior Design 35, Korean Institute of Interior Design: 86-92.

Lee, Dong Gi (2002) A study on the Interior Traits by User Group of Department Store - With Priority Given to Preference of User Groups. Master Thesis, KonKuk University: 56-84.

Lee, Hye Jin, Seo, Hee Sook, and Lee, Sang Hong (2007) "A Study on the Interior Image Analysis of Large-scale Discount Store - Focused on the Interior Composition Elements." Journal of the Architectural Institute of Korea, Planning \& Design, 23 (2), Architectural Institute of Korea: 47-54.

\section{SOURCES OF ORIGINAL IMAGES}

\begin{tabular}{ll}
\hline Picture No. & Source \\
\hline A01 & http://www.jtodutyfree.com \\
A02 & http://blog.naver.com/11100811/80086204646 \\
A12 & http://blog.naver.com/11100811/80086204646 \\
B01 & Jennifer, Hudson.(2007) Interior Architecture Now. \\
B02 & Laurence King Publishing LTD, pp.152-153 \\
B03 & http://www.petermarinoarchitect.com \\
B04 & http://www.oma.eu/ \\
B05 & http://www.claudiosilvestrin.com/ \\
B06 & Jennifer, Hudson.(2007) Interior Architecture Now. \\
& Laurence King Publishing LTD, pp.328-329 \\
B07 & Jennifer, Hudson.(2007) Interior Architecture Now. \\
B08 & Laurence King Publishing LTD, pp.214-215 \\
B09 & http://cafe.naver.com/lanvin2/166 \\
B10 & http://pentagram.com \\
Jennifer, Hudson.(2007) Interior Architecture Now. \\
B11 & Laurence King Publishing LTD, pp.340-341 \\
h12 & Jennifer, Hudson.(2007) Interior Architecture Now. \\
B13 & Laurence King Publishing LTD, pp.58-59 \\
B14 & http://www.baciocchi.it \\
B15 & http://www.armani5thavenue.com \\
\hline &
\end{tabular}

(Date of Submission : 2010.9.6) 